\section{Surgeons' Performance Determining the Amount of Graft Material for Sinus Floor Augmentation Using Tomography}

Adriana Dibo Cruz' ${ }^{1}$ Guilherme Alvares Peixoto ${ }^{2}$, Marcelo Freitas Aguiar1, Gabriela Alessandra Cruz Galhardo Camargo ${ }^{1}$, Nicolas Homs ${ }^{1}$
'Specific Formation Dept., Dental School, UFF - Universidade Federal Fluminense, Nova Friburgo, RJ, Brazil ${ }^{2}$ Postgraduate Program, Dental School, UFF - Universidade Federal Fluminense, Nova Friburgo, RJ, Brazil

Correspondence: Adriana Dibo Cruz, Rua Dr. Silvio Henrique Braune 22, 28625-650 Nova Friburgo, RJ, Brazil. Tel: +55-22-2528-7168. e-mail: adrianadibo@gmail.com

\begin{abstract}
This study aimed to assess the performance of surgeons in determining the amount of graft material required for maxillary sinus floor augmentation in a preoperative analysis using cone-beam computed tomography images. A convenience sample of 10 retrospective CBCT exams (i-CAT ${ }^{\circledR}$ ) was selected. Scans of the posterior maxilla area with an absence of at least one tooth and residual alveolar bone with an up to $5 \mathrm{~mm}$ height were used. Templates $(n=20)$ contained images of representative cross-sections in multiplanar view. Ten expert surgeons voluntarily participated as appraisers of the templates for grafting surgical planning of a $10 \mathrm{~mm}$ long implant. Appraisers could choose a better amount of graft material using scores: 0) when considered grafting unnecessary, 1) for $0.25 \mathrm{~g}$ in graft material, 2) for $0.50 \mathrm{~g}, 3)$ for $1.00 \mathrm{~g}$ and 4) for $1.50 \mathrm{~g}$ or more. Reliability of the response pattern was analyzed using Cronbach's $\alpha$. Wilcoxon and Mann-Whitney tests were performed to compare scores. Regression analysis was performed to evaluate whether the volume of sinuses $\left(\mathrm{mm}^{3}\right)$ influenced the choose of scores. In the reliability analysis, all values were low and the score distribution was independent of the volume of the maxillary sinuses ( $p>0.05$ ), which did not influence choosing the amount of graft material. Surgeons were unreliable to determine the best amount of graft material for the maxillary sinus floor augmentation using only CBCT images. Surgeons require auxiliary diagnostic tools to measure the volume associated to $\mathrm{CBCT}$ exams in order to perform better.
\end{abstract}

Key Words: CT imaging; diagnosis, sinus floor elevation, bone substitutes.

\section{Introduction}

After a tooth loss, typically the alveolar bone is progressively resorbed. This situation is significantly more challenging in the posterior maxilla than in other areas, owing to the possibility of a maxillary sinus pneumatization. Therefore, for proper oral rehabilitation with dental implants in this area, sinus floor augmentation and accurate placement of graft materials is critical (1). Second, time to implant placement varies depending on the conditions of the residual bone, which may occur along with the sinus surgery floor augmentation and placement of graft materials or after bone regeneration.

Currently, there is a wide range of graft materials, including autogenous, allografts, xenografts and alloplasts, which can be used alone or in combination in different surgical techniques for sinus floor augmentation. Every graft material has a specific indication; however, all are used to provide proper support for the clot during the early healing phase, apart from supporting the bone regeneration process by direct or indirect stimulation (2).

Autogenous bone has been considered the gold standard of grafting materials, owing to its highly osteogenic potential, despite its immediate disadvantages, such as the difficulty of obtaining a sufficient amount and the need of a secondary surgical site. These disadvantages led to the development of alternative and supplementary grafting materials. A further problem occurring during bone regeneration is the volumetric reduction of grafting material over time, which occurs in different ways with different types of material. Volumetric change has been frequently and reliably observed to lead to insufficient bone volume, frustrating oral rehabilitations using implants (3-5).

The outcome of sinus floor augmentation depends upon several factors; not only those related to grafting materials, but also those related to anatomical characteristics of the maxillary sinus that have played a significant role in this process (1). Notwithstanding the challenges of sinus floor augmentation, in which there is need to determine the minimum amount of graft material considering the volume for this surgical procedure (1), graft volume changes have not yet been strictly established (6). Thus, this study aimed to assess the performance of dental implant surgeons to determine the amount of graft material required for maxillary sinus floor augmentation in a preoperative analysis using cone-beam computed tomography images.

\section{Material and Methods}

After approval by the Ethics Committee in Research, 
which complies with the Helsinki Declaration, a convenience sample was retrospectively selected. The sample size for this study was calculated based on formula: [Sw $]^{\wedge} 2=\mathrm{N}^{\wedge} 2$ $(2 n(m-1)$, where "Sw" is within-subject standard deviation (value=1.96), " $\mathrm{N}$ " is a extrapolation of a population that needs implant (value $=10 \%$ ), " $\mathrm{m}$ " is the number of measurements per sample (quantities of observers and images per exam), and " $n$ " is the number of sample. A minimum sample size of 5 CBCT exams was needed to obtain 95\% confidence interval for a repeatability test. Nevertheless, a larger sample was used to prevent any loss to follow-up (reduction in " $m$ ").

The eligible sample consisted of 10 patients submitted to CBCT exams between November 2014 and April 2015 in a private clinic of oral radiology. Participants signed a free informed term of consent (FITC) and agreed to participate in this study. All exams were selected from non-vulnerable groups and participants ranged from 35 to 60 -years old. The main inclusion criterion was that the CBCT exam was

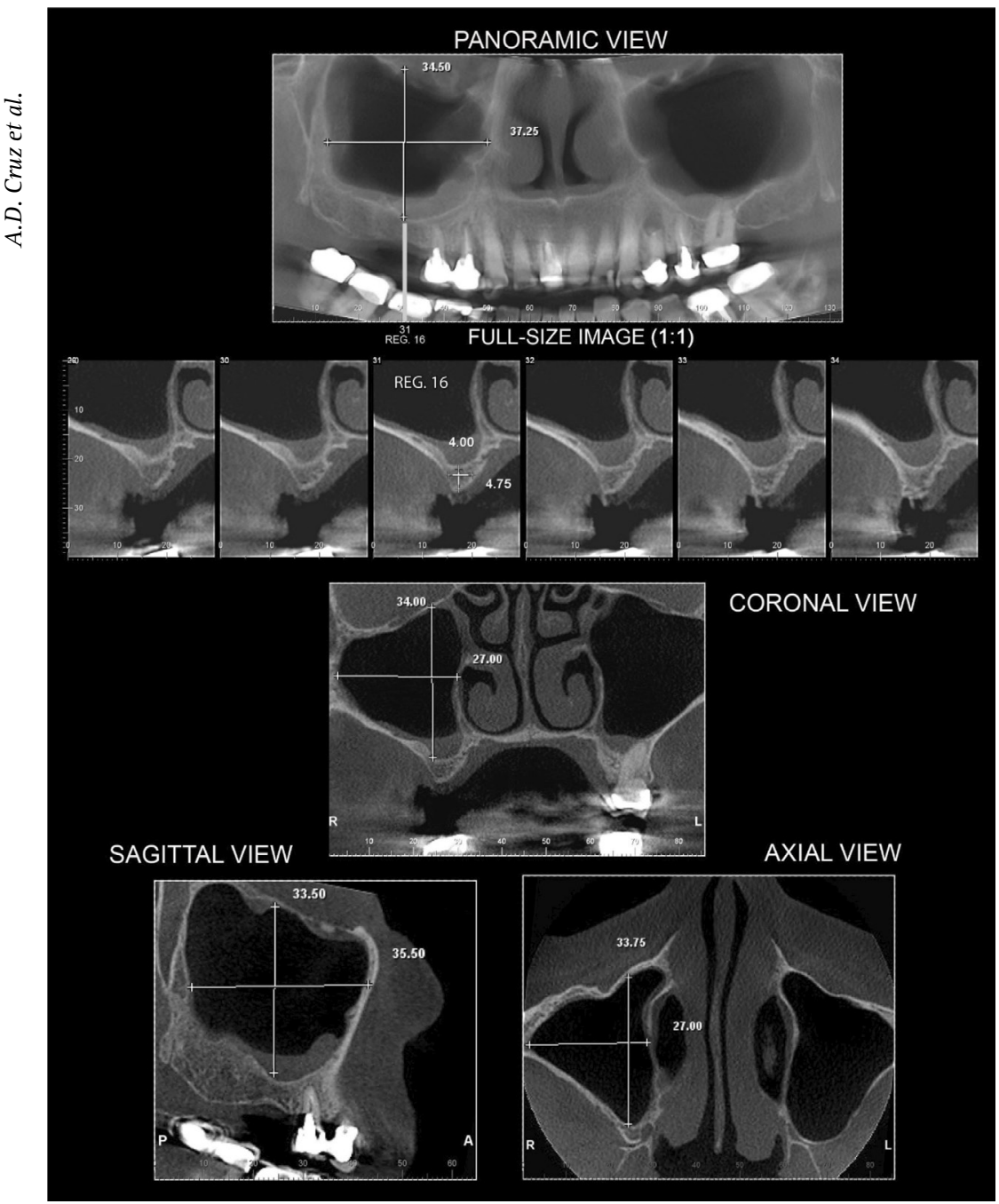

Figure 1. Representative image of templates used in study. acquired for surgical diagnosis of sinus floor augmentation that would be necessary prior to both surgical procedures, grafting and implant placement. Another inclusion criterion was posterior maxilla area with an absence of at least one tooth (from maxillary first premolars to the maxillary second molar) and residual alveolar bone with an up to 5 $\mathrm{mm}$ height. Exclusion criteria included history of previous maxillary sinus surgery or other surgeries in the maxillary area, whether reconstructive, pre-prosthetic or implants, besides exams with low resolution and no written informed consent signed by the patients.

The CBCT exams were acquired in an i-CAT ${ }^{\circledR}$ (Imaging Sciences International, LLC, Hatfield, PA, USA) tomograph, following the same protocol for maxilla, field of view (FOV) of $6 \times 16 \mathrm{~cm}, 0.25 \mathrm{~mm}$ voxel size and approximately $40 \mathrm{~s}$ acquisition time at $120 \mathrm{kV}$ and 3-8 mA. An expert oral radiologist recorded the images for the study using tomography-specific software (XoranCat ${ }^{\circledR}$ Version 3.1.62, Xoran Technologies, Ann Arbor, MI, USA). The expert selected representative cross sections in multiplanar view (axial, coronal, sagittal and panoramic) of each tomography exam to make the templates (Fig. 1) standardized at this clinic for surgical diagnosis of sinus floor augmentation. The images in templates had linear measures indicating all distances of maxillary sinus and residual alveolar bone (height, width and depth). In order to prevent a memory effect in appraisers, two templates $(n=20)$ were confectioned for each exam, with the same content. All images were rotated in the horizontal axis, turning left side to right side or vice versa.

Ten oral surgeons with more than six years of clinical experience in sinus floor augmentation, grafting and implant placement surgery and familiar with tomographic exams, volunteered to participate as appraisers in this study. The appraisers were instructed in a single session with the purpose of presenting the templates and explaining the scoring method for determining the amount of graft material required for the maxillarysinus floor augmentation. For surgical graft planning, a subsequent implant of $10 \mathrm{~mm}$ in length placed in the edentulous area should have 
been contemplated. Thus, the appraiser would be free to choose the better amount of the required graft material, in accordance with their surgical planning, using the following scores: 0) for those who consider unnecessary rehabilitation of the area with grafting, 1) for those who would use up to $0.25 \mathrm{~g}$ graft, 2) for those who would use up to $0.50 \mathrm{~g}$ graft, 3) for those who would use up to 1.00 $\mathrm{g}$ graft and 4) for those who would use $1.50 \mathrm{~g}$ or more graft. The appraiser initially received the first 10 templates and independently recorded this first evaluation without any time limit. One month the first evaluation, appraisers received the second set of templates, with other 10 templates of rotated images, as explained before, to obtain intra-observer reliability. Once again the time to finish the second evaluation was unlimited.

To establish the maxillary sinus volume, all exams in DICOM format were imported and analyzed with the ITK/ SNAP software (http://www.itksnap.org/pmwiki/pmwiki. php) by segmenting the total volume of these sinuses (Fig. 2). ITK/SNAP software is an open source medical image-computing platform for biomedical research, which enables visualization in different planes (axial, coronal and sagittal) and manipulation of images, optimized by tridimensional reconstructions. The segmentation was made by a single trained and calibrated observer, who performed manual delineation of the inner surface of sinuses, carefully following its anatomical borders in the axial section, complementing the sagittal and coronal sections of the image by active contour methods. After complete segmentation of sinuses, ITK/SNAP software was used to calculate the total volume of this structure in cubic millimeters $\left(\mathrm{mm}^{3}\right)(7)$.

Reliability of the response pattern of each appraiser at intra- and inter-observer analysis in relation to the amount of graft material required for the maxillary sinus floor augmentation was analyzed using Cronbach's $\alpha$ Scores from the first and the second evaluations were compared using the Wilcoxon test and the scores assigned to each quartile were compared by the Mann-Whitney test. Regression analysis was used to evaluate whether the volume of sinuses $\left(\mathrm{mm}^{3}\right)$ influenced which scores appraisers chose. All statistical analyses were conducted with a significance level set at $5 \%(\alpha=0.05)$.

\section{Results}

The total volume of maxillary sinuses ranged from $1055.83 \mathrm{~mm}^{3}$ (minimum) to $1808.55 \mathrm{~mm}^{3}$ (maximum). For standardization of measurement levels for statistical analysis, the volume (in $\mathrm{mm}^{3}$ ) was converted to an ordinal scale using the quartile $(01=1187.75 ; 02=1348.53$; $03=1389.82$ ). Thus, output values in the data set were ranked as follows: 1) minimum $<01$; 2) $01<02$; 3) $02<03$; 4) $03<$ maximum.

In the reliability response pattern of the appraisers about the amount of graft material required for maxillary sinus floor augmentation, internal consistency values ranged from

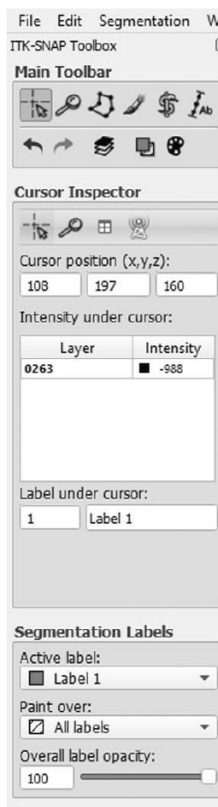

3D Toolbar

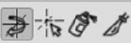
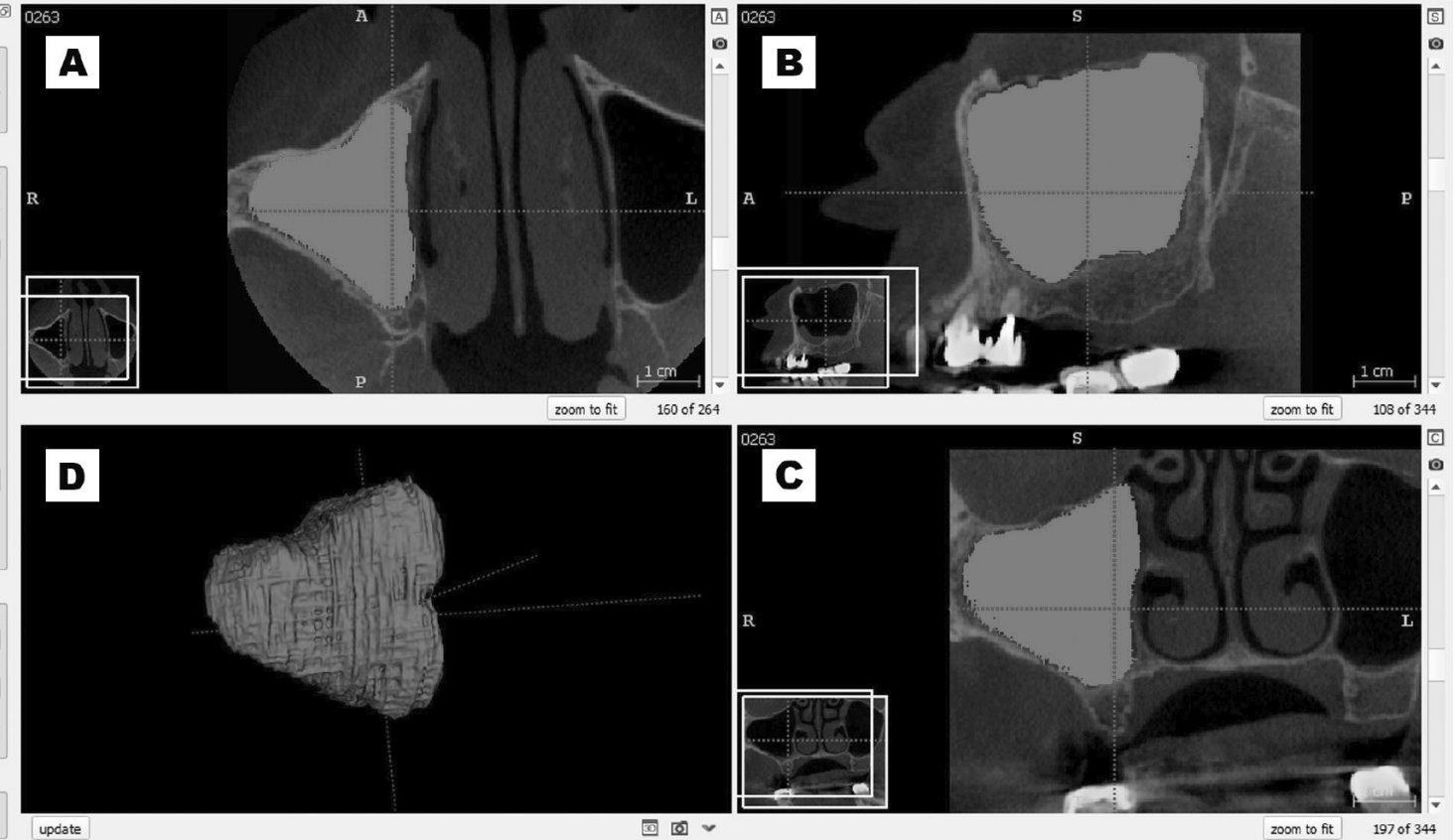

Figure 2. Representative image of segmentation of the maxillary sinus. In "A" axial view, in "B" sagittal view, in "C" coronal view, in "D" tridimensional view of segmentation 
poor to good ( $0.5333 \leq a / p h a \geq 0.8989)$ in the intraobserver analyses, i.e. repeatability. Internal consistency values were acceptable at both points of evaluation (alpha $=0.7255$ for the first time and alpha $=0.7789$ for the second) in the interobserver analyses, i.e. reproducibility. Reliability response pattern of appraisers correlated with total volume of sinuses, with internal consistency values ranging from unacceptable to poor $(0.0971 \leq a l p h a \geq 0.5333)$.

The score distribution of the response pattern of appraisers with regard to quartile attached to total volume of the maxillary sinuses is shown in Figure 3. Table 1 shows the output of the statistical analysis of the comparison of scores for amount of graft material required for the maxillary sinus floor augmentation and total volume of maxillary sinuses. In general, the medians of scores differed little between the groups ( $p>0.05$ ), differing only in comparison between time evaluations in that the fourth quartile received a broader range of scores $(p<0.05)$, and in comparison between quartiles in that the second quartile of the first evaluation had a narrower range than the higher score $(p<0.05)$. Figure 4 shows the polynomial regression analysis with low-fit ( $R 2=0.6559)$ to determine scores by

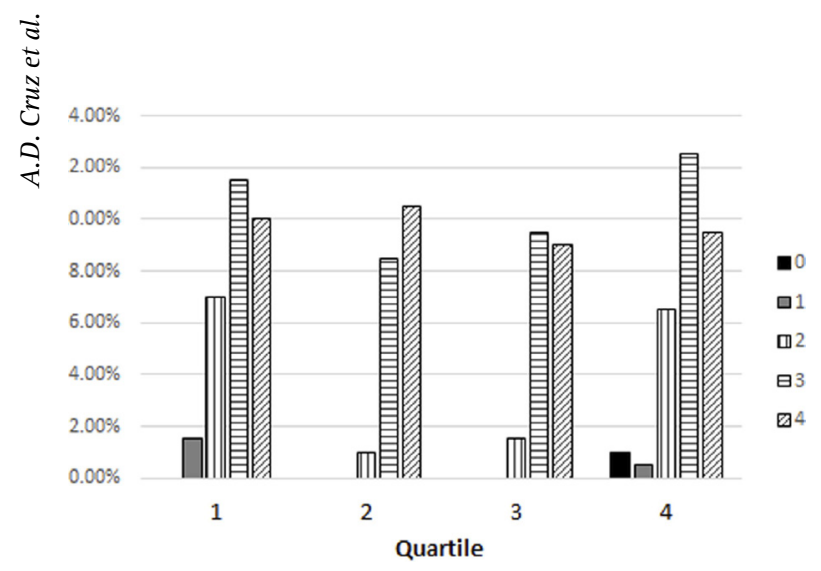

Figure 3. Score distribution of the response pattern of appraisers with regard to quartile attached to total volume of the maxillary sinus. appraisers in accordance with sinus volume $\left(\mathrm{mm}^{3}\right)$.

\section{Discussion}

Patients with a demand for oral rehabilitation using dental implants in the posterior maxilla area often need sinus floor augmentation and placement of graft materials. This procedure is well documented, with long-term success in Implantology (2,8-10). However, success in such a procedure is not always possible. Several factors can lead to failure, resulting in a great volumetric reduction of the graft $(4,11,12)$, making rehabilitation impossible. There are some evidences suggesting that dimensions of maxillary sinus cavity may affect healing by formation of granulation tissue (1), but this correlation is not yet completely accepted (13). On the other hand, in this study was assessed only the surgeons' performance to determine the amount of graft material required for the maxillary sinus floor augmentation. In this way, preoperative analysis using images of cone-beam computed tomography determined the reliability of choices of a specific amount of graft material and in which way this choice was connected with the maxillary sinus volume. However, this study contained

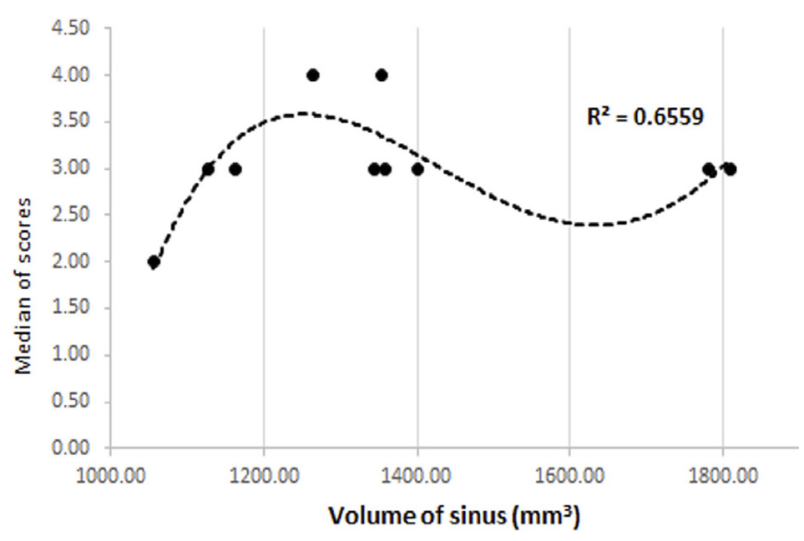

Figure 4. Regression analysis of score medians and volume of sinuses $\left(\mathrm{mm}^{3}\right)$.

Table 1. Median (minimum-maximum) of the scores for amount of graft material required for the maxillary sinus floor augmentation in accordance to total volume of the maxillary sinuses

\begin{tabular}{lcccc}
\hline & \multicolumn{3}{c}{ Total volume $\left(\mathrm{mm}^{3}\right)$} \\
\cline { 2 - 5 } & $1055.83-1187.75$ & $1187.75-1348.53$ & $1348.53-1389.82$ & $1389.82-1808.55$ \\
\hline Quartile* $^{1}$ & $1 \mathrm{n}=4)$ & $2(\mathrm{n}=6)$ & $3(\mathrm{n}=6)$ & $4(\mathrm{n}=4)$ \\
1st evaluation & $3(1-4) \mathrm{A} \mathrm{a}$ & $4(3-4) \mathrm{A} \mathrm{b}$ & $3.5(2-4) \mathrm{A} \mathrm{ab}$ & $3(2-4) \mathrm{A} \mathrm{a}$ \\
2nd evaluation & $3(1-4) \mathrm{A} \mathrm{ab}$ & $3.5(2-4) \mathrm{A} \mathrm{a}$ & $3(2-4) \mathrm{A} \mathrm{ab}$ & $3(0-4) \mathrm{B} \mathrm{b}$ \\
\hline
\end{tabular}

Same letters (upper case in columns and lower case in rows) represent groups that did not differ significantly (using Wilcoxon test for evaluations, Mann-Whitney for quartiles, $\mathrm{p}>0.05$ ). *The $\mathrm{n}$ total of sample per quartile considering the sum of evaluations. 
neither the reasons for the choices or their consequences.

The reliability of surgeons' responses about the amount of graft material required for maxillary sinus floor augmentation was low. There was a weak correlation among appraisers' replies over time referring to low repeatability, compared to the replies of others referring to low reproducibility and to maxillary sinus volume referring to low accuracy. Thus, independent from the reasons for the decision each surgeon took into account when making his/her choice of amount of graft material, the results revealed that this choice was randomly attributed. An important observation was that appraisers could have evaluated all cases carefully and unhurriedly because there was no time limit for each set of exams to be completed, in either evaluation. An additional relevant fact was that after the one-month interval, when evaluations and templates were repeated with rotated images on the horizontal plan, the appraisers had presumably forgotten the first evaluation; there were no improvements in performance during the second evaluation. This observation is important, confirming the absence of common assessment criteria to better determine the amount of graft material in accordance with the surgical planning. To the best of the authors' knowledge, this reliability of response patterns has not been previously investigated or demonstrated in the literature.

The sample of the present study showed maxillary sinuses of total volumes ranging from $1055.83 \mathrm{~mm}^{3}$ (minimum) to $1808.55 \mathrm{~mm}^{3}$ (maximum). These volumes are compatible with those in previous studies $(12,14,15)$, although there were variations owing to gender, age, and characteristics of the dentition and ethical group. However, the methodology for measuring the maxillary sinus may influence considerably the volume; the internal anatomy of maxillary sinuses is very complex and irregular, with presence of septs and other anatomical variations. Only specific software to calculate the actual segmented volume can be used to this measurement, providing accurate volume measurements by images $(7,14,16)$. Prior to such use of segmented tridimensional images, the methods were more laborious and less precise. For example, maxillary sinus volumes were obtained by linear measures using casts of the maxillary sinus with dental impression material (17). On the other hand, despite the sinuses of the sample presenting large range of volumes, the scores selected as a better amount of graft material differed little from this volume variation. No linear relation was obtained between an increase of maxillary sinuses and a large amount of graft material.

Actually, understanding of volume is the great problem approached in the present study. The unit of graft material is weight $(\mathrm{g})$ and all image mensuration unit is length (width, height and thickness), there is no software available for implant planning that has a tool of conversion unit for equivalences; besides, each graft material has a specific density (weight per volume), which are not known yet. Furthermore, it must be emphasized that the results of this study illustrated the underuse of complex exams with high radiation dose. The surgeons demonstrated the absence of common assessment criteria (repeatability and reproducibility) in evaluating CBCT for surgical planning. Arias-Irimia et al. (18) have previously reported the need to analyze the volume measurements of the maxillary sinuses before performing the surgery using image segmentation programs, preferably together with those used to plan dental software, as reliable tools that can be used quickly, easily and for free. In addition, there is need to know the density of each graft material. Thus, the planned surgery will be more complete when it includes in the evaluation the real volume of the area for grafting and all the predictions of maximal resorption indexes for each graft material. According to the results of this study, the surgeon was unreliable to determine the best amount of graft material for the maxillary sinus floor augmentation in a preoperative analysis using images of cone-beam computed tomography. Thus, surgeons need auxiliary diagnostic tools for volume measurements associated to CBCT exams for a better performance.

\section{Resumo}

0 objetivo deste estudo foi avaliar o desempenho dos cirurgiões na determinação da quantidade de material de enxerto necessária para a elevação do assoalho do seio maxilar em uma análise pré-operatória, utilizando imagens de tomografia computadorizada de feixe cônico. Foi selecionada uma amostra de conveniência de 10 exames retrospectivos CBCT (i-CAT ${ }^{\circledR}$ ). Os exames foram da área da maxila posterior que possuíam ausência de pelo menos um dente e com osso alveolar residual de altura igual ou inferior a $5 \mathrm{~mm}$. Os templates $(n=20)$ continham imagens de secções transversais representativas numa vista multiplanar. Dez experientes cirurgiões voluntariamente participaram como avaliadores dos templates para o planejamento cirúrgico de enxerto para um implante de $10 \mathrm{~mm}$ de comprimento. Os avaliadores escolheram a melhor quantidade de material de enxerto usando os escores: 0) quando o enxerto era desnecessário, 1) para $0,25 \mathrm{~g}$ de enxerto, 2) para $0,50 \mathrm{~g}, 3)$ para $1,00 \mathrm{~g}$, e 4) para $1,50 \mathrm{~g} \mathrm{ou}$ mais. A confiabilidade do padrão de resposta foi analisada utilizando a $\alpha$ de Cronbach. Os testes de Wilcoxon e Mann-Whitney foram utilizados para comparar os escores. A análise de regressão foi realizada para avaliar se o volume dos seios $\left(\mathrm{mm}^{3}\right)$ influenciou a escolha dos escores. $\mathrm{Na}$ análise de confiabilidade, todos os valores foram baixos e a distribuição dos escores foi independente do volume dos seios maxilares ( $p>0,05), 0$ que não influenciou a escolha da quantidade de material de enxerto. Os cirurgiões apresentaram falta de confiabilidade ao determinar a melhor quantidade de material de enxerto para o aumento do assoalho do seio maxilar utilizando somente as imagens de TCFC. Assim, os cirurgiões necessitam de ferramentas de diagnóstico auxiliares para mensuração de volume associada à TCFC para um melhor desempenho.

\section{Acknowledgements}

The authors express their special thanks to oral surgeons that volunteered to participate as appraisers in the present study. 


\section{References}

1. Zheng $X$, Teng M, Zhou F, Ye J, Li G, Mo A. Influence of maxillary sinus width on transcrestal sinus augmentation outcomes: radiographic evaluation based on cone beam CT. Clin Implant Dent Relat Res 2016;18:292-300.

2. Corbella $S$, Taschieri S, Weinstein R, Del Fabbro M. Histomorphometric outcomes after lateral sinus floor elevation procedure: a systematic review of the literature and meta-analysis. Clin Oral Implants Res 2016;27:1106-1122.

3. Berberi A, Bouserhal L, Nader N, Assaf RB, Nassif NB, Bouserhal J, et al.. Evaluation of three-dimensional volumetric changes after sinus floor augmentation with mineralized cortical bone allograft. J Maxillofac Oral Surg 2015;14:624-629.

4. Kirmeier R, Payer $M$, Wehrschuetz $M$, Jakse $N$, Platzer $S$, Lorenzoni $M$. Evaluation of three-dimensional changes after sinus floor augmentation with different grafting materials. Clin Oral Implants Res 2008;19:366-372.

5. Mazzocco F, Lops D, Gobbato L, Lolato A, Romeo E, del Fabbro M. Threedimensional volume change of grafted bone in the maxillary sinus. Int J Oral Maxillofac Implants 2014;29:178-184.

6. Umanjec-Korac S, Parsa A, Darvishan Nikoozad A, Wismeijer D, Hassan B. Accuracy of cone beam computed tomography in following simulated autogenous graft resorption in maxillary sinus augmentation procedure: an ex vivo study. Dentomaxillofac Radiol 2016:20160092 [Epub ahead of print].

7. Yushkevich PA, Piven J, Hazlett HC, Smith RG, Ho S, Gee JC, et al.. User-guided 3D active contour segmentation of anatomical structures: significantly improved efficiency and reliability. Neuroimage 2006;31:1116-1128.

8. Danesh-Sani SA, Loomer PM, Wallace SS. A comprehensive clinical review of maxillary sinus floor elevation: anatomy, techniques, biomaterials and complications. Br J Oral Maxillofac Surg 2016;54:724730.

9. Carreno Carreno J, Aguilar-Salvatierra A, Gomez-Moreno G, Garcia Carreno EM, Menendez Lopez-Mateos ML, Perrotti V, et al.. Update of surgical techniques for maxillary sinus augmentation: a systematic literature review. Implant Dent 2016:20160092. [Epub ahead of print].

10. Esposito M, Grusovin MG, Rees J, Karasoulos D, Felice $P$, Alissa R, et al. Effectiveness of sinus lift procedures for dental implant rehabilitation: a Cochrane systematic review. Eur J Oral Implantol 2010;3:7-26.

11. Gultekin BA, Cansiz E, Borahan O, Mangano C, Kolerman R, Mijiritsky $E$, et al.. Evaluation of volumetric changes of augmented maxillary sinus with different bone grafting biomaterials. J Craniofac Surg 2016;27:e144-e148.

12. Berberi A, Nader N. Subantral augmentation with mineralized cortical bone allograft material: clinical, histological, and histomorphometric analyses and graft volume assessments. Implant Dent 2016;25:353360.

13. Favato MN, Vidigal BC, Cosso MG, Manzi FR, Shibli JA, Zenobio EG. Impact of human maxillary sinus volume on grafts dimensional changes used in maxillary sinus augmentation: a multislice tomographic study. Clin Oral Implants Res 2015;26:1450-1455.

14. Mohlhenrich SC, Heussen N, Peters $F$, Steiner T, Holzle F, Modabber A. Is the maxillary sinus really suitable in sex determination? A threedimensional analysis of maxillary sinus volume and surface depending on sex and dentition. J Craniofac Surg 2015;26:e723-726.

15. $\mathrm{Oz} \mathrm{AZ}, \mathrm{Oz} \mathrm{AA}, \mathrm{El} \mathrm{H}$, Palomo JM. Maxillary sinus volume in patients with impacted canines. Angle Orthod 2017;87:25-32.

16. Lopes SL, Costa AL, Gamba TO, Flores IL, Cruz AD, Min LL. Lateral pterygoid muscle volume and migraine in patients with temporomandibular disorders. Imaging Sci Dent 2015;45:1-5.

17. Uchida $Y$, Goto $M$, Katsuki $T$, Akiyoshi T. A cadaveric study of maxillary sinus size as an aid in bone grafting of the maxillary sinus floor. J Oral Maxillofac Surg 1998;56:1158-1163.

18. Arias-Irimia O, Barona Dorado C, Gomez Moreno G, Brinkmann JC, Martinez-Gonzalez JM. Pre-operative measurement of the volume of bone graft in sinus lifts using CompuDent. Clin Oral Implants Res 2012;23:1070-1074.

Received December 5, 2016 Accepted March 14, 2017 